\title{
Reducing the use of imprisonment. Lessons from Probation Day Centres in
}

England and Wales: 1970-2000

\begin{abstract}
Day Reporting Centres as an alternative to prison have become a feature of the Criminal Justice Systems of most States in America. In contrast, Day Centres have virtually disappeared from the curricula of Probation services in England and Wales. In this paper we look back on the the short history of day centre provision in this country and examine what can be learned from its different forms and assess the viability of reintroducing the concept as a means of significantly reducing the use of imprisonment this side of the Atlantic.
\end{abstract}

A half a century ago, the concept of day centre provision as an alternative to custody saw the light of day in England and Wales (Mair 1988; Vanstone 1985) and soon after in 1986, in what could possibly be a rare example of criminal justice policy being transferred from the United Kingdom to the USA, an Alternative Incarceration Center was established in Connecticut (Phillips 1986). Although recently established centres acting as alternatives to prison for women, continue to fly a flag for the concept (MoJ 20150), day centres for men have virtually disappeared from the UK probation prospectus, whereas our survey of day reporting centres in America has identified more than 750 examples of Day Reporting Centers (DRCs) - almost exclusively for male participants - in all fifty mainland States of North America, plus one in Hawaii. In addition, there are 495 Youth Reporting and Evening Reporting Centers for younger people convicted of criminal offences (Priestley \& Vanstone 2021). In a sense their development has mirrored the variations and complexity of the story of how Day Centres took shape in Britain. The DCR regimes in California have ranged from highly structured, non-residential programs utilizing supervision, sanctions and services coordinated from a central location (Nieto 1998) to community-based options providing punishment and control while simultaneously assisting with rehabilitation and reintegration (Wong et al 2019) and to what the Los 
Angeles County Probation Department in 2019 calls a Reentry Opportunity Center for probationers and their families (Ridley-Thomas No Date). It is against this backdrop, and within the context of the future structure and purpose of probation being decided this side of the Atlantic that we examine critically the story of the rise and fall of day centres in England and Wales, explore the forms they took and the reasons for their diversity, reflect on what light the story might throw on the current conflicting visions of what the future probation service might look like, and consider the viability and possible value of reintroducing a form of day centre provision similar to that in the USA. That story, part of which provided some insights into the vexed issues of control and choice in relation to the purpose and practice of rehabilitation, began with a review of the experiences of shortterm prisoners released from four local prisons (Vercoe 1970).

Although in the early 1970s when the the idea of day centres first emerged as a feature of the criminal justice system, 'the Probation Service was a thoroughly respected and takenfor-granted presence within the English (sic) Criminal Justice system '(Nellis 2007: 49) the drums of correctionalism, central control and reduced autonomy, increased accountability, public protection and punitive ideology were distant but distinctly audible (Garland 2001). Moreover, the social, cultural and political environment of the United Kingdom was different to that of today, and the service was not yet in the purview of political ideologues. With hindsight, however, its vulnerability to changes that would transform the criminal justice system during the next few decades is clear to see.

At the very beginning of that decade, the Labour government commissioned the Advisory Council on the Penal System (1970) to investigate the viability of non-probation community based sentences for people over seventeen. A sub-committee chaired by Baroness Wootton reviewed the potential of community service, the expansion of 
attendance centres, semi-custodial penalties, and day centres. While the subsequent report did not recommend day centres - and in fact was rather tepid on the issue of rehabilitation - it did conclude that community service underpinned by the idea of making reparation and doing worthwhile work might encourage good lives. A change of government seems to have saved the day centre idea because the newly elected Conservative government not only introduced community service on to the statute book via the Criminal Justice Act 1972 but in addition was persuaded that intensive supervision and social training might be an appropriate alternative to custody for some people and, therefore, launched the Day Training Centre (DTC) experiment. A research project focused on six hundred and fourteen men who had been discharged from local prisons in Bristol, Cardiff, Gloucester and Swansea prisons and a related proposal that a community centre might be an effective way of catering for the needs of short-term prisoners had clearly influenced the government's thinking (Vercoe 1970; Priestley 1970).

The tenuous nature of the Service's credibility and the beginnings of uncertainty about its role, typified on the one hand by the Younger Report (Advisory Council 1974) with its promotion of supervision and control orders as a means of countering the 'soft option' characterisation of probation and the idea of the inherent moral goodness of probation on the other (Celnick and McWilliams 1991), is in some senses illustrated by the different forms of Day Centres that developed over the next few decades. Interestingly and in retrospect, perhaps not surprisingly, these were associated with three models of probation namely voluntarism (for example, the Barbican Centre in Gloucester) in which the focus was on a those who attended being central to decision-making unconstrained by the dictates of conditions; surveillance or controlism (the Kent Control Unit) with its concern about creating a form of probation that was credible to the judiciary; and non-treatment or personalist (the Day Training Centres) (Senior 1984: Raynor 1985) also concerned with 
choice and respect for persons but within the framework of court-imposed conditions. Such diversity reflects the fact that while the probation service was overseen by the Home Office individual service areas (and their managers) had a considerable amount of autonomy and freedom to introduce innovative and experimental practice. However, it was a diversity encompassed in some broad commonalities in role and purpose, namely, the diversion from custody of appropriate people and the reduction of inappropriate custodial sentences; exploration of offending behaviour; enhancement of social and life skills; and the development of problem-solving skills that might reduce offending. These otherwise distinct models emerged in what with hindsight can be discerned as three reasonably distinct phases, the first that began with the Day Training Centre (DTC) experiment, the second that followed the Criminal Justice Act 1982, and the third that began after the arrival of the 'What Works 'project in the early part of the 1990s (Robinson 2002).

\section{Voluntary and semi-structured Day Centres}

Predictably, the open door policy of Voluntary Day Centres, not all of them run by probation services but invariably closely linked to them, and some offering conditional attendance such as those in Gloucester (the Barbican Centre), Lincoln, Liverpool (Whitechapel Centre), London (Sherborne House), Nottingham (St. Mary's House) Pontefract, Sheffield (Westside Day Centre) and Surrey (APP Day Centre), led to engagement with a wide range of people. Advocates of such centres argued that the standard probation order with its traditional conditions offered not only the opportunity of social work help but also the right to choose help, and they were critical of the constraint imposed on choice by conditions (Scarborough et al 1987). Embodying a kind of professional counter-culture, the proposed centres promoted informed choice and a focus on socio-economic problems in addition to the opportunity to explore non-offending ways of resolving problems. The Lincoln Centre, for example, provided an activity-based drop- 
in facility with taster groups to encourage participation in induction groups in which selfassessment helped shape contracts of individually tailored programme participation. These more formal groups included a group focused on the specific offence of burglary and a more practical group that encouraged a legitimate interest in motor vehicles (Scarborough et al 1987). The centre used open records compiled collaboratively by officer and probationer, the latter owning responsibility for change.

Set up in 1973, the Barbican was initially a voluntary centre with close links to the probation service (Burney 1980; Wright 1985). ${ }^{\mathrm{i}}$ It provided a drop-in facility not just for ex-prisoners and probationers but for all the marginalised, displaced and disadvantaged people of Gloucester whose efforts at survival were problematic (Foggart 1976). As in the Lincoln Centre, users could choose casual contact or become members of the centre by entering into a formalised agreement of help that significantly, was founded on the belief that "change in social performance $[\ldots]$ would have the greatest chance of success if the individuals involved had a genuine sense of belonging to the same group, creating as far as possible, a non-subordinate relationship between the staff and the "client" group' (Foggart 1976: 93). In point of fact, the achievement of such relationship, deemed the most significant result of Foggart's study, owed much to the Barbican's involvement with the pioneering New Careers project in which people with an offending history were trained as social workers (Priestley 1975). ${ }^{2}$ Exciting and innovative though it undoubtedly was, by 1974 it became clear that the centre was no longer viable as a charitable organisation and that if it was to survive the probation service would need to assume responsibility. It did so in 1975 thus ensuring its survival but to the detriment of the 'peer learning community' principle as staff became organised 'along more orthodox and hierarchical lines '(Foggart 1976: 5). Of the other voluntary centres, the Whitechapel centre in Liverpool catered specifically for the homeles); St. Mary's House ran an open door drop-in facility plus a 
mother and child group twice a week; and the Westside Day Centre was open to homeless men and women though its no children policy meant that usage by women was low (Wright 1985). Alongside these, semi-structured day centres evolved in Sherborne House, London, which was mainly voluntary but included a small number of young unemployed probationers attending under court conditions (Fairhead 1981); Pontefract, which catered for voluntary probationers who had not been helped by normal supervision but had a small number of people attending under conditions (Rowntree 1971); and the Alternative Probation Project (APP) in Farnham, Surrey (organised on a fifty-fifty basis by a charity and the probation service), which offered forms of group therapy for men and women aged between 17 and 25 that Burney (1980) judged to be similar to those in Grendon Underwood.

\section{The Kent Control Unit.}

If the disputation over conditions was divisive what unfolded in the garden of England was seen by many in the service as the antithesis to probation values. In 1980, with an eye on the Report of the Advisory Council on the Penal System (Advisory Council 1970) and its suggestion that the probation service should try to divert a wider range of people from prison, the Chief Probation Officer of Kent set up a working party of senior officers briefed to examine the feasibility of providing intensive supervision as a realistic alternative to custody primarily for 17 to 24 year olds but for some older people too, the emphasis being unreservedly on intense and realistic.

The working party recommended a one year probation order involving six months attendance, an $11 \mathrm{pm}$ to $5 \mathrm{am}$ curfew, and supervision from 9am to $10 \mathrm{pm}$ from Monday to Friday and from 9am to $4 \mathrm{pm}$ on a Saturday. Those in full time employment would report directly to the Control Unit from work; and those people unemployed would attend the 
Medway Centre (a version of the Day Training Centres) from 9am to 5pm and from there to the Control Unit. Each week probationers would be required to attend at least two community-based Adult Education classes, a social skills course delivered by a specialist teacher within the unit, and another of their own choosing. For the remaining evenings, probationers were to be occupied in a group meeting, domestic cleaning and some form of physical recreation whilst Saturday activities involved a mixture of work and leisure. Minor infringements would result in community service. The commitment to punishment in the community (several years before government policy embraced it) is evident in the claim that 'in real terms the Probation Control Unit exceeds in severity any institutional sentence currently available to the Magistrates Court for a single offence'. Finally, as if offering some reassurance about the traditional value base of the service, it was envisaged 'that the atmosphere within the [Unit] will be relaxed and of a positive nature' (Kent Probation and After-Care Service 1980: 4).

A few years later, in 1985, another working party recommended the retention of the Medway Centre and the abolition of the Control Unit because it had not been particularly effective in reducing offending, it cost more than Detention Centres, referrals were low, and tellingly, although they supported the Unit magistrates viewed it as 'an inappropriate task for the Probation Service (Spencer and Edwards 1986: 93). Subsequent policy embraced a dual approach of voluntary day centre and Day Training Centre provision, but it is the Control Unit philosophy, despite its demise, that on reflection might be adjudged to be more in tune with the political ideology that would shape the probation service in the early part of the 21 st century. Punishment in the community had had its first brief airing in public: it would soon become the Service's official motif.

\section{Day Training Centres}


Priestley's paper (1970), put forward the idea of a community centre whose programme would be based on building people's strengths through skills training designed to reduce deficits in role performance. It advocated a shift away from the medical or treatment model towards one closer to notions of personal development, vocational, and life skills training growing out of recent work in social psychology (Argyle 1969). In retrospect the design appears to have anticipated some features of the 'Reasoning and Rehabilitation' model later promulgated in Canada (Ross et al 1988).

Clearly, the centres that would form the basis of the Day Training Centre experiment in England and Wales were influenced by these ideas but they would assume a variety of different forms in their early development and would cater not just for the rootless, shortterm prisoners of Vercoe's (1970) survey but also people with more serious offending histories. In what was intended to be a two year experimental period monitored by the Home Office Research Unit four centres were established in Liverpool, London, Pontypridd and Sheffield for a two year experimental period with a remit to develop their own programmes. During the experimental period each centre constructed very different programmes but as a meeting of the four directors with the Home Office shows they purported to share, as alternatives to custody, common aims of helping probationers in 'self awareness', self confidence', 'self survival 'and 'techniques of behaviour that will enable him to survive, help him sustain satisfying relationships, communicate with others, decision making, considering of others in his environment and other people's needs '[...] involve people in examining their behaviour and taking responsibility for it [and] creating a break with delinquent groups [and helping] them look at why they commit crimes'. Intriguingly, further examination of the minutes reveals some tensions and disagreement. Bob Spiers of the Home Office Probation Inspectorate pointedly questioned the mutuality of aims when he said 'you are all so very different. I feel that you are tending to gloss over 
the differences rather than examining them'. In addition, on the question of reducing offending one Director doubted the possibility of preventing offending as a direct aim instead advocating that 'our work is toward integrating the man into society so that he need not, or doesn't want to offend 'and another stated that 'if you concentrate specifically on law keeping you have no real basis for change: you need a deeper level of change'. ${ }^{i}$ Similar tensions between the Directors and the Home Office are laid bare in a meeting earlier in the year at which the lead researcher presented his research document:

'There was a great deal of dissatisfaction expressed about the content of the report - it was out of date, there was an absence of hard data, the participant observation took place at a time when the Centres were unsure of their role, that three Centres had evolved to the position where the original programmes were unrecognisable'. iii

It is little surprise, therefore, that the research report was never published, apart from a short inconclusive Home Office Research Bulletin (Smith 1982), and that in the late 1970s and early 1980s the DTCs unwittingly promoted an ad hoc, and some thought illconsidered, development of Day Centres within the probation service generally (Burney 1980). Most of the Centres opted for statutory rather than voluntary attendance by using section 2 of the 1973 Powers of the Criminal Court Act to require people to attend the Day Centre programmes. Following an appeal against a breach of probation action (Cullen v. Rogers), the Law Lords ruled against the service on the grounds that people should not be subject to 'unfettered control of a probation officer'(Weekly Law Reports 1982, vol. 1, pp. 729-45). In that same year, the Criminal Justice Act introduced schedule 11 that replaced section 4 of the Powers of the Criminal Court Act 1973, the legal framework for the Day Training Centres, with $4 \mathrm{a}$ (requiring the probationer to 'present himself to a person or persons specified in the order at a place or places so specified') and $4 \mathrm{~b}$ (requiring the 
probationer 'to participate or refrain from participating in activities specified in the order' on specified days during the probation order). This led to two types of day centre: 'the more informal, voluntary 4a type [and] the 'alternative to custody' $4 \mathrm{~b}$ type, 'a hybrid of the DTCs and the old day centres (Mair 1988: 2).

Estimates of the number of probation services having some form of day centre facility at the end of the 1970s and beginning of the 1980s vary, 28 according to Burney (1980) and 42 according to Fairhead (1981), but by the second half of the 1980s (post 1982 Criminal Justice Act) day centre development had accelerated so that there were 80 in England and Wales (Mair 1988). Of course, programmes in these centres varied but the advent of what became known as 'What Works 'meant that by 1995 all but six of services had at least one centre facility though now mostly called probation centres providing 'a more rigorous and structured [groupwork] approach '(Mair and Burke 2012: 144). A limited number of programmes were designed to address issues of discrimination. For example, the Inner London Service established the Woman's Probation Centre in which the focus was on the particular personal and offence-related needs of women (Durrance and Ablitt 2001), and the Hereford and Worcester Project eschewed the content and structure of men's programmes and replaced them with ones drawn from women's perspectives (Roberts 2002). In Greater Manchester the Black Offender Groupwork Programme used black tutors and black mentors to help probationers to empower and skill probationers (Williams 2006). Although these initiatives, like day centres themselves, foundered in the face of the ascendancy of the surveillance and control model, if not at a practice but certainly at a policy level, and the growth of political interference that would lead inexorably to the privatisation of the service, the story does not end there. 
At the beginning of the new century, one Women's Probation Centre was just about surviving (Durrance and Ablitt 2001), providing as it was an alternative to custody for what were deemed to be high risk women. It involved a 30 day programme centred on offence analysis, confronting discrimination faced by women, relationship management, and health and employment issues, all underpinned by an holistic ethos of empowerment. Reconviction rates were positive; nevertheless, the researchers concluded that an intensive programme of this kind was 'a viable alternative to custody provided women can be steered through to completion' (258). Despite this encouraging conclusion, the centre seems to have been the last to be run by the probation service following what Worrall describes as 'countless missed opportunities and disgracefully uncertain funding for numerous innovative programmes for women' (Worrall 2016: 354) and the initiation of a policy throughout England and Wales of dispersal of organisational responsibility to the community. Subsequently, in line with the general direction of the recommendations in the Corston Report (2007), Women's Centres or 'independent specialist community support services for women facing multiple disadvantage' including those who had come before the courts (Women's Budget Group 2020: 9), some of them receiving NOMS and/or Probation Trust funding, were set up in England. In an analysis of 39 of these centres and 597 attendees reoffending rates were found to be five percent less than a matched control group, and while not statistically significant were considered by the researchers to be encouraging (Ministry of Justice 2015). Eventually, however, many of the centres 'exhausted the funding options that [had] kept them afloat' and were not helped by limited funding from the government (Women's Budget Group 2020: 15).

As well as these centres the probation service took advantage of the development of community based hubs in which agencies shared premises and other facilities and brought together resources pertinent to issues such as education and training, employment, health, 
money matters and accommodation (Phillips et al 2020). These enabled Community Rehabilitation Companies (CRCs) 'to deliver a service without the need for expensive service user facing officers and interview rooms' (265). In her study of three such hubs Dominey (2018) illustrates the varied nature of CRC involvement: in the first, two CRC officers worked one of two days a week, in the second one officer attended every afternoon, and in the third - a CRC led pop up hub in a rented church building and open two days a week - CRC staff worked jointly with those from other organisations. Just as with Women Centres the future of these initiatives lies in the balance as the direction of a once again nationalised probation service is decided.

\section{Conclusion}

It is clear that in their various forms, the centres exemplified the arguments and controversies that would dominate thinking about the purposes, values and practice of the Probation Service in the final years of the $20^{\text {th }}$ century and the beginning of the $21^{\text {st }}$. They embraced voluntarism and collaborative relationships, controlism and coercive rehabilitation, and non-treatment life and social skills training, so what might policy makers, managers and practitioners learn from the day centre idea that might help the restructuring of the newly renationalised service? What were the pluses and minuses of the broad day centre project?

The use by the early voluntary centres of the probation order confined to traditional conditions preserved the right to choose what might be described as social work help and, it was argued, increased the likelihood of self-motivation to embrace change. Proponents of voluntarism emphasised informed choice, a focus on socio-economic problems (social capital in theories of desistance parlance), probationer participation in problem-solvingcentred contracts and an open door policy that allowed involvement of families and other 
users (Scarborough et al 1987). This was the antithesis of the Kent Control Unit experiment and its overtly punitive elements and strict and restrictive conditions, all of which proved to be contra to the positive ethos required to motivate and encourage efforts to change. Moreover, their prime selling point of credibility to the courts proved to be defective. In a sense, the Day Training Centres and the Day Centres they gave rise to can be seen as a compromise offering choices made under constraint (Raynor 1978), in some cases preserving the right to choose problem-solving help and offering a credible alternative to custody to the courts (Vanstone 1993). None were properly evaluated. It is the voluntary model, however, that resonates with the more recent developments in relation to Women Centres and hubs and they have the advantage of being able to engage directly and appropriately with the needs of disadvantaged people. Yet their functionality as alternatives to custody is far less certain and as has been described above they are vulnerable to vagaries of governmental funding policy. Such centres and hubs clearly have a place in future community provision, but a serious assault on the excessive use of imprisonment in England and Wales suggests, we argue, requires consideration being given to the reintroduction of some form of day centre provision in the new probation service.

The issues of choice, engagement in change effort, effectiveness and credibility are as relevant now as they were then and any future attempts to reintroduce some kind of meaningful day centre provision as part of probation's curriculum would have to address them. Meaningful choice was made redundant when probation was made a sentence in its own right and consent eschewed. It seems self evident that personal commitment to engage in rehabilitative effort depends to a significant degree on motivation and acceptance of the need to change both circumstances and personal rehabilitative strengths, so reestablishing the concept of consent is pivotal to achieving them. Of course, that would 
not mean potential probationers having an unconstrained choice. Issues of justice and public protection demand otherwise. Raynor (1978) made an interesting distinction between coercion and choices made under constraint and that might still offer the best way forward if a form of day centre provision is to be introduced. The option of an opportunity to accept involvement in a programme of reimagined rehabilitation (Burke et al 2019) and restrictions on personal liberty in place of a custodial sentence not only seems reasonable but sustains probation's commitment to justice and public protection, and presents a genuine case for being credible to the courts. The ethos and culture of the UK voluntary centres and the majority of the conditional centres of the past and the recent Hubs Women's Centresplus perhaps something that resembles the US Re-entry Opportunity Center concept (Ridley-Thomas nd), could help create the kind of environment most conducive to encouraging and motivating probationers to engage constructively in strengths-based rehabilitative work. Finally, any such policy initiative would be expensive and, therefore, would have to go hand in hand with a substantial reduction in the use of imprisonment. The funds thus released could finance a research programme that would seek to determine the efficacy of the changes and continuously support a professional culture of self-reflection and flexibility in relation to both policy and practice. That would require a level of political courage sadly lacking in recent years.

\section{References}

Advisory Council (1970) Non-Custodial and Semi-Custodial Penalties (Report of the Advisory Council on the Penal System). London: H.M.S.O 
Advisory Council (1974) Young Adult Offenders. Report of the Advisory Council on the Penal System. London: HMSO.

Argyle, M. (1969). Social Interaction. London: Methuen.

Burke, L., Collett, S. and McNeill, F. (2019) Reimagining rehabilitation. Beyond the individual. London: Routledge.

Burney, E. (1980) A Chance to Change, London: Howard League for Penal Reform.

Celnick, A. And McWilliams, W. (1991) 'Helping, Treating and Doing Good', Probation Journal, 38, 4, 164-170.

Corston, J. (2007) The Corston Report: A review of women with particular vulnerabilities in the criminal justice system. London: Home Office

Dominey J (2018) The Use of Community Hubs to Deliver Probation Supervision. Cambridge: Institute of Criminology. Available at: https://www.ccgsj.crim.cam.ac.uk/research/ community-hubs (accessed18th June 2021).

Durrance, P. and Ablitt, E. (2001) “Creative solutions” to women's offending: An evaluation of the women's probation centre', Probation Journal 48, 4, 247-259.

Fairhead, S. and Wilkinson-Grey, J. (1981) Day Centres and Probation (Home Office Research Unit Paper 4), London, Home Office. 
Foggart, R. H. (1976) The Barbican Centre: An Analysis of the Helping Relationship, Gloucester, Gloucestershire Probation Service.

Garland, D. (2001) The Culture of Control, Oxford: Oxford University Press.

Kent Probation and After-Care Service (1980) The Widening Scope of the Probation and After-Care Service. Unpublished Working Party Report. Maidstone: Kent Probation and After-Care Service.

Mair, G. (1988) Probation Day Centres. London, HMSO.

Mair, G. and Burke, L. (2014) Redemption, Rehabilitation and Risk Management. A History of Probation. London: Routledge.

Ministry of Justice Data Lab. (2015) Re - offending Analysis: Women's Centres throughout England. Justice Statistical Analytical Services.

Nellis, M. (2007) 'Humanising justice: the English Probation Service up to 1972', in L. Gelsthorpe and R. Morgan (Eds) Handbook of Probation. Cullompton: Willan Publishing.

Nieto, Marcus (1998) Probation for Adult and Juvenile Offenders: Options for Improved Accountability. Sacramento. California Council on Criminal Justice.

Phillips, Joel. (1986) Technical Assistance Report No. 006A to the Alternative 
Incarceration Center, Connecticut Prison Associates (sic). American University

Washington DC. Bureau of Justice Assistance. (June 27, 1986)

Phillips, J., Albertson, K., Collinson, B. And Fowler, A. (2020) '’Delivering desistanceFocussed probation in community hubs. Five key ingredients', Probation Journal 67, 3, 264-282.

Priestley, P. (1970) The Problem of the Short Term Prisoner. Cheltenham: NACRO.

Priestley, P. (1975) 'New Careers: Power sharing in Social Work', in H. Jones (Ed) Towards a New Social Work. London: Routledge, Kegan \& Paul.

Priestley, P. and Vanstone, M. (2021) Gazetteer of Day Reporting and Evening Reporting Centers in the United States. Work in progress.

Raynor, P. (1978) 'Compulsory persuasion: a problem for correctional social work', British Journal of Social Work 8, 411-24.

Raynor, P. (1985) Social Work, Justice and Control. Oxford : Basil Blackwell.

Ridley-Thomas, Mark. Supervisor. Second District. (nd). One-Stop-Shop for Second Chance Opportunities. County of Los Angeles (nd).//ridleythomas.lacounty.gov/index.php/los-angeles-county-opens-one-stop-shop-for-secondchance-opportunities/ 
Roberts, J. (2002) 'Women-centred: The West Mercia community-based programme for women offenders', in P. Carlin (Ed) Women and Punishment: The Struggle for Justice. Cullompton: Willan Publishing.

Ross, R. R., Fabiano, E. A. (1988) 'Reasoning \& Rehabilitation', International Journal of Offender Therapy and Comparative Criminology 32, 1, 29-35.

Rowntree, M. (1971) An introduction to intermediate treatment, Probation,17(1), 18-20.

Scarborough, J., Geraghty, J. and Loffhagen, J. (1987) 'Day centres and voluntarism', Probation Journal 34, 2, 47-50.

Senior, P. (1984) 'The probation order: vehicle of social work or social control?', Probation Journal, 31, 2, 64-70.

Smith, L.J.F. (1982) Day Training Centres (Home Office Research Unit Bulletin No.14). London: H.M.S.O.

Spencer, N. and Edwards, P. (1986) 'The Rise and the Fall of the Kent Control Unit', Probation Journal 33, 3, 91-4.

Vanstone, M. (1985) 'Moving away from help? Policy and practice in probation day centres', Howard Journal, 24, 1, 20-28. 
Vanstone, M. (1993) A 'Missed Opportunity 'Re-assessed: the Influence of the Day Training Centre Experiment on the Criminal Justice System and Probation Policy and Practice, The British Journal of Social Work. 23, 3, 213-229

Vercoe, K. (1970). 'Men Leaving Local Prisons: some characteristics of 614 cases'. Cheltenham. NACRO.

Williams, P. (2006) 'Designing and delivering programmes for minority ethnic offenders', in S. Lewis., P. Raynor., D. Smith and A. Ward ask (Eds) Race and Probation. Cullompton: Willan Publishing.

Women's Budget Group (2020) The Case for Sustained Funding for Women's Centres. A Report from the UK Women's Budget Group. Available at wbg.org.uk (accessed $16^{\text {th }}$ June 2021)

Wong J, S, Bouchard J, Lee, C, and Gushue, K, (2019) Examining the effects of day reporting centers on recidivism: A meta-analysis. Journal of Offender Rehabilitation 58(3): 240-260.

Worrall, A. (2016) 'Personal reflections on an honourable profession', in M. Vanstone and P. Priestley (Eds) Probation and Politics. Academic Reflections from Former Probation Officers.London: Palgrave MacMillan.

Wright, A. (1985) The Day Centre in Probation Practice (Social Work Monograph 22). Norwich: University of East Anglia. 
${ }^{\mathrm{i}}$ In the mid 1980s the Barbican Centre was converted to a statutory Day Centre.

ii Verbatim minutes of DTC Directors at the Home Office on the 20th May 1976. Present: Molly Samuels, Peter Soord, R. Spiers, Stephen Stanley, John Adams, Pam Strong, Dennis Tunney, Barry Ashe, James McGuire and Derek Day.

iii Minutes of DTC Directors meeting held on the 6th January 1976. Present: London DTC - Dennis Tunney, Stephen Stanley (ACPO research), Sheffield DTC - Peter Soord, Robin Smith (Psychologist), Liverpool DTC - John Adams, Barry Ashcroft (Psychologist), Pontypridd DTC - Derek Day. 